\title{
Truncus arteriosus and truncal valve regurgitation
}

\author{
Efrén Martínez-Quintana ${ }^{1,2}$, Francisco Portela-Torrón ${ }^{3}$ \\ ${ }^{1}$ Cardiology Service, Insular-Materno Infantil University Hospital, Las Palmas de Gran Canaria, Spain; ${ }^{2}$ Medical and Surgical Sciences Department, \\ Faculty of Health Sciences, University of Las Palmas de Gran Canaria, Las Palmas de Gran Canaria, Spain; ${ }^{3}$ Cardiac Surgery Service, Dr. Negrín \\ University Hospital of Gran Canaria, Las Palmas de Gran Canaria, Spain \\ Correspondence to: Efrén Martínez-Quintana. Servicio de Cardiología, Complejo Hospitalario Universitario Insular Materno Infantil, Avd. Marítima \\ del Sur s/n. 35016 Las Palmas de Gran Canaria, Spain. Email: efrencardio@gmail.com. \\ Provenance: This is an invited article commissioned by the Section Editor Xicheng Deng (Department of Cardiothoracic Surgery, Hunan Children's \\ Hospital, Changsha, China). \\ Comment on: Naimo PS, Fricke TA, d'Udekem Y, et al. Impact of truncal valve surgery on the outcomes of the truncus arteriosus repair. Eur J \\ Cardiothorac Surg 2018;54:524-31.
}

Submitted Jan 30, 2019. Accepted for publication Feb 20, 2019.

doi: $10.21037 /$ tp.2019.02.01

View this article at: http://dx.doi.org/10.21037/tp.2019.02.01

Truncus arteriosus is a congenital heart disease in which a great artery, that is balanced positioned above a large ventricular septal defect, gives origin to the ascending aorta, the pulmonary arteries and the coronary circulation. The atrioventricular septum, both ventricles and the left ventricular outflow tract are usually normal. In most cases the common trunk gives rise to the main pulmonary artery which then bifurcates into branch pulmonary arteries generally of normal size. Truncal valve is usually dysplastic with thickened and deformed leaflets and in order from highest to lowest frequency it may be trileaflet, quadricuspid or bicuspid. The absence of one pulmonary artery is rare (1).

Aortic anomalies such as right aortic arch, aberrant subclavian artery, interrupted aortic arch and hipoplastic aortic arch are frequent (2-4). In fact many surgeons prefer to use the Van Praagh classification (5), instead of the Collet and Edwards classification (6) based on pulmonary architecture, as it recognizes patients with underdeveloped aortic arch (hypoplastic or interrupted) with a large patent ductus arteriosus connected to the descending aorta (15\% of the patients with truncus arteriosus). In such patients origin of the pulmonary arteries from the trunk is usually abnormal. However in 2000, a three categories classification was proposed (2) which included truncus arteriosus with confluent or near confluent pulmonary arteries, absence of one pulmonary artery or truncus arteriosus with associated interrupted aortic arch or aortic coarctation.

Clinically the truncus arteriosus results in different scenarios: (I) pulmonary congestion and cardiac heart failure due to pulmonary volume overload, (II) the development of pulmonary arterial hypertension due to the high pressure flow at the pulmonary level if the truncus arteriosus is not corrected in the neonatal period and (III) cyanosis secondary to the mixture of oxygenated and nonoxygenated blood due to a non-restrictive ventricular septal defect and a common arterial trunk. In fact, although less than $1 \%$ of congenital heart disease patients are due to truncus arteriosus it accounts for $4 \%$ of all critical cases (7).

From a surgical point of view, the truncus arteriosus was firstly managed with bilateral pulmonary artery banding to avoid high pressure blood flow. Later on, definitive surgical correction with a single-stage repair with closure of the ventricular septal defect and valveless conduits from the right ventricle to the pulmonary artery were carried out followed up by the implant of valved allografts or conduits containing porcine valves (1). In the last 30 years most patients have been managed by early primary repair predominantly as neonates to reduce pulmonary arterial hypertension (8-11). Remarkably, the overall mortality reported by Ebert et al. (11) in 1984 is pretty similar to actual reports with most of these deaths occurring in patients with significant preoperative truncal valve regurgitation.

So, the impact of significant truncal vale insufficiency, that occurs in $25 \%$ of truncus arteriosus patients (12), is a matter of concern as it has been identified as a risk factor for 
a poor outcome $(10,11,13-15)$ and for subsequent truncal valve surgery if not addressed at primary repair $(9,16)$. Anyway, all at the expense of a higher risk of mortality compared with those who did not require valve intervention probably due to an increased complexity attested by the higher utilization of mechanical circulatory support and longer length of stay (15). Nevertheless, reoperation after primary repair is frequent. Kaza et al. (9), for example, found a reoperation rate of $70 \%$ and $50 \%$ at 5 and 7 years respectively, Myers et al. (17) reported a need for reoperation of $9 \%, 45 \%$ and $77 \%$ at 1,5 , and 10 years respectively advising the creation of a tricuspid truncal valve to provide the best outcomes and Henaine $e t a l$. (16) found that freedom from truncal valve reoperation was $96 \%, 82 \%$ and $63 \%$ at 1,10 and 18 years respectively emphasizing the importance of more refined techniques of truncal valve plasty.

Therefore we are at a crossroads of when and how to operate truncal valve regurgitation in truncus arteriosus patients. Trivial or mild truncal valve regurgitation has in general a good outcome while patients with severe regurgitation do not. Therefore, severe regurgitation should be addressed at the primary operation. However, doubts arise in patients with moderate truncus valve regurgitation.

To shed light on these patients Naimo et al. (18) focused on 80 patients with truncus arteriosus and truncal valve regurgitation. Sixty-one (76\%) had mild, 17 (21\%) had moderate and $2(2.5 \%)$ patients had severe truncal valve regurgitation in the preoperative echocardiography. Patients with moderate or severe regurgitation showed more frequently quadricuspid valves. Sixty-three percent of patients with moderate or severe regurgitation underwent concomitant truncal valve surgery with a $25 \%$ early mortality and $81 \%$ of patients required truncal valve reparation at a median follow-up time of 20 years. However, neonatal truncal valve surgery was not identified as a risk factor for mortality and the need for aortic arch surgery did not impact on the progression of truncal valve insufficiency. All techniques carried out to achieve truncal valve surgery are nicely described in the article. On the other hand and in a surprising way, in truncus arteriosus patients with moderate truncal valve regurgitation and no concomitant valve surgery the need for reoperation occurred in $43 \%$ of the cases while the degree of truncal valve insufficiency was reduced from moderate to mild in almost $30 \%$ of them.

Interestingly, they did not identify either quadricuspid valve morphology or moderate to greater insufficiency as risk factors for mortality on univariable analysis although mortality is clearly higher in patients with moderate to severe regurgitation. Maybe with more patients this would be significant and in agreement with others. Another significant aspect is the more than twice risk of reoperation when the valve is quadricuspid. Overall rate of quadricuspid valve is $30 \%, 57 \%$ in patients with concomitant valve surgery, and $79 \%$ in those with moderate to severe regurgitation, making this morphology a concern for the authors. Evolution to regurgitant lesion in this kind of lesion, even in normal hearts, is well recognized (19). Finally, neonatal surgery is an always more technical demanding population, with higher mortality. In this series a high proportion of neonates is reported, one third, with a $30 \%$ with interrupted aortic arch repair associated. Even so, mortality is high but not significant among patients with or without truncal valve repair.

Although the authors, based on their results recommend that children with moderate or greater truncal valve regurgitation and a quadricuspid valve should undergo concomitant truncal valve surgery they also state that due to heterogeneity in truncal valve morphology and surgical techniques, it is difficult to determine a specific surgical approach that offers the most durability. The authors conclude that rather than attempting to come up with the standardized technique of repair, one must individualize repair for each patient.

In our experience primary surgical repair should be performed in the neonatal period facing truncal valve repair if there is significant valve regurgitation. The advantages of truncal valve reconstructive surgery, despite an evident learning curve, include the natural postoperative valve hemodynamics and the avoidance of oral anticoagulation or structural valve deterioration. As newer methods of aortic valve reconstruction, similar to mitral repair, are achieving excellent outcomes we can be optimistic with truncal valve disease. Although some uncertainty exists about the best valve reconstruction surgery we think that the understanding of the mechanisms leading to truncal valve insufficiency in addition to an individualized approach that includes leaflet correction techniques and the reconstruction of the annulus if necessary will entail lower risks of valve-related complications in the medium to long term follow-up.

\section{Acknowledgments}

None. 


\section{Footnote}

Conflicts of Interest: The authors have no conflicts of interest to declare.

\section{References}

1. Castañeda AR, Jonas RA, Mayer JE, et al. Cardiac Surgery of the Neonate and Infant. Truncus arteriosus. Sunnders Company 1994:281-93.

2. Konstantinov IE, Karamlou T, Blackstone EH, et al. Truncus arteriosus associated with interrupted aortic arch in 50 neonates: a Congenital Heart Surgeons Society study. Ann Thorac Surg 2006;81:214-22.

3. Butto F, Lucas RV Jr, Edwards JE. Persistent truncus arteriosus: pathologic anatomy in 54 cases. Pediatr Cardiol 1986;7:95-101.

4. Nath PH, Zollikofer C, Castaneda-Zuniga W, et al. Persistent truncus arteriosis associated with interruption of the aortic arch. Br J Radiol 1980;53:853-9.

5. Van Praagh R, Van Praagh S. The anatomy of common aorticopulmonary trunk (truncus arteriosus communis) and its embryologic implications. A study of 57 necropsy cases. Am J Cardiol 1965;16:406-25.

6. Collett RW, Edwards JE. Persistent truncus arteriosus; a classification according to anatomic types. Surg Clin North Am 1949;29:1245-70.

7. Reller MD, Strickland MJ, Riehle-Colarusso T, et al. Prevalence of congenital heart defects in metropolitan Atlanta, 1998-2005. J Pediatr 2008;153:807-13.

8. Bove EL, Lupinetti FM, Pridjian AK, et al. Results of a policy of primary repair of truncus arteriosus in the neonate. J Thorac Cardiovasc Surg 1993;105:1057-65.

9. Kaza AK, Burch PT, Pinto N, et al. Durability of truncal

Cite this article as: Martínez-Quintana E, Portela-Torrón F. Truncus arteriosus and truncal valve regurgitation. Transl Pediatr 2019;8(5):360-362. doi: 10.21037/tp.2019.02.01 valve repair. Ann Thorac Surg 2010;90:1307-12.

10. Hanley FL, Heinemann MK, Jonas RA, et al. Repair of truncus arteriosus in the neonate. J Thorac Cardiovasc Surg 1993;105:1047-56.

11. Ebert PA, Turley K, Stanger P, et al. Surgical treatment of truncus arteriosus in the first 6 months of life. Ann Surg 1984;200:451-6.

12. Vohra HA, Whistance RN, Chia AX, et al. Long-term follow-up after primary complete repair of common arterial trunk with homograft: a 40-year experience. J Thorac Cardiovasc Surg 2010;140:325-9.

13. Di Donato RM, Fyfe DA, Puga FJ, et al. Fifteen-year experience with surgical repair of truncus arteriosus. J Thorac Cardiovasc Surg 1985;89:414-22.

14. Brown JW, Ruzmetov M, Okada Y, et al. Truncus arteriosus repair: Outcomes, risk factors, reoperation and management. Eur J Cardiothorac Surg 2001;20:221-7.

15. Russell HM, Pasquali SK, Jacobs JP, et al. Outcomes of repair of common arterial trunk with truncal valve surgery: a review of the society of thoracic surgeons congenital heart surgery database. Ann Thorac Surg 2012;93:164-9.

16. Henaine R, Azarnoush K, Belli E, et al. Fate of the truncal valve in truncus arteriosus. Ann Thorac Surg 2008;85:172-8.

17. Myers PO, Bautista-Hernandez V, del Nido PJ, et al. Surgical repair of truncal valve regurgitation. Eur J Cardiothorac Surg 2013;44:813-20.

18. Naimo PS, Fricke TA, d'Udekem Y, et al. Impact of truncal valve surgery on the outcomes of the truncus arteriosus repair. Eur J Cardiothorac Surg 2018;54:524-31.

19. Hayakawa M, Asai T, Kinoshita T, et al. Quadricuspid aortic valve: a report on 10-year case series and literature review. Ann Thorac Cardiovasc Surg 2014;20:941-4. 